\title{
"Homem é homem e mulher é mulher, o resto, sem-vergonhice": representações sociais da transexualidade sobre comentários da internet
}

"A man is a man and a woman is a woman; everything else is hanky-panky": social representations of transsexuality on internet comments

\author{
Marieli Mezari Vitali ${ }^{a}$ \\ (D) https://orcid.org/0000-0003-0052-7788 \\ E-mail: marielimezariळgmail.com \\ Amanda Castrob \\ (D) https://orcid.org/0000-0002-8666-4494 \\ E-mail: amandacastropsळgmail.com \\ Jaime Caravaca-Morerac \\ (iD) https://orcid.org/0000-0002-6647-217X \\ E-mail: jaimealonso.caravaca®ucr.ac.cr \\ Jacks Soratto \\ (iD) https://orcid.org/0000-0002-1339-7268 \\ E-mail: jacksळunesc.net \\ aniversidade Federal de Santa Catarina. Florianópolis, SC, Brasil. \\ bUniversidade do Extremo Sul Catarinense. Criciúma, SC, Brasil. \\ 'Universidade da Costa Rica. Escola de Enfermagem. San José, \\ San Pedro, Costa Rica.
}

\section{Correspondência}

Jacks Soratto

Av. Universitária, 1.105. Criciúma, SC, Brasil. CEP 88806-000.

\section{Resumo}

O objetivo deste estudo foi identificar as representações sociais sobre transexualidade com base nos comentários descritos nas redes sociais (Facebook e Instagram). Trata-se de um estudo com abordagem qualitativa do tipo exploratório descritivo, utilizando-se o método da pesquisa documental e alicerçada na teoria das representações sociais. Os dados foram coletados a partir de uma série de reportagens de um programa jornalístico brasileiro de impacto nacional. A análise de dados foi realizada com base na análise de conteúdo com o auxílio do software Atlas.ti. Os resultados oportunizaram a geração de 14 códigos, que foram agrupados em quatro categorias: origem da transexualidade, atitude em relação à transexualidade, definição de transexualidade e vulnerabilidade trans. Foi possível identificar a ausência de informação dos internautas, em especial a falta de respeito com as pessoas transexuais, justificada por um discurso culpabilizador, opressor e fundamentalista que coopera para a vulnerabilidade delas, alocando-as às margens da sociedade de direito. Os resultados concluíram que é necessário ampliar políticas públicas eficazes para a população trans e, dessa forma, promover a garantia de seus direitos humanos e cidadania.

Palavras-chave: Transexualidade; Identidade de Gênero; Representações Sociais; Internet; Redes Sociais; Pesquisa Qualitativa.. 


\section{Introdução}

The objective of this study was to identify social representations about transsexuality based on the comments described in social networks (Facebook and Instagram). This is a qualitative study with a descriptive exploratory approach, using the method of documentary research and based on the theory of social representations. Data were collected from some series of reports of a Brazilian journalistic program with national impact. Data analysis was performed based on content analysis with the aid of Atlas.ti software. The results allowed the generation of 14 codes, which were grouped into four categories: origin of transsexuality, attitude towards transsexuality, definition of transsexuality and trans vulnerability. It was possible to identify the lack of information of the internauts, especially the lack of respect for the transsexual people, justified by a blaming, oppressive, fundamentalist speech that cooperates for their vulnerability, allocating them at the margins of the society of right. These results conclude that it is necessary to expand effective public policies for the transgender population and thus guarantee the human rights and citizenship for these people.

Keywords: Transsexuality; Gender Identity; Social Representations; Internet; Social Networks; Qualitative Research..
No ano de 2016 houve em torno de 1.876 violações de direitos humanos da população LGBT no Brasil (Brasil, 2016). De acordo com os dados da Antra, no ano de 2017 ocorreram 179 assassinatos de pessoas autoidentificadas dentro do espectro trans no Brasil, sendo 169 travestis e mulheres trans e 10 homens trans. Nesse contexto de violência, é possível estimar que a cada 48 horas uma pessoa trans é assassinada (Antra, 2018). Ainda, 2.609 pessoas transgêneros foram mortas em 71 países entre janeiro de $2008 \mathrm{e}$ setembro de 2017 (Fedorko; Berredo, 2017).

Cabe ressaltar que a mídia muitas vezes não respeita a identidade de gênero da vítima, tratando travestis como homossexuais e homens trans como lésbicas, o que de acordo com a Associação Nacional de Travestis e Transexuais (Antra) (2018) dificulta o levantamento de dados, podendo ter um percentual de assassinatos de pessoas trans maior do que o indicado. No entanto, para compreender tais claustros sociais faz-se importante definir três conceitos que muitas vezes se tornam difusos na prática e nos imaginários coletivos, o que por sua vez acarretam a (re)produção de informações distorcidas: sexo assignado ao nascimento, orientação sexual e identidade de gênero.

O sexo, na perspectiva de Machado (2005), surge como uma categoria médico-diagnóstica, algo identificado e legitimado por um profissional da medicina. Entretanto, utiliza-se o termo "sexo assignado ao nascimento" tendo em vista a impossibilidade de discutir o sexo sem que seja a partir do gênero. Portanto, não é a partir da natureza que se criam as dicotomias, e sim que se aprende a perceber o mundo como dicotômico, havendo intolerância para a indefinição e a ambiguidade (Machado, 2005).

Assim, nos permitimos então, a partir da experiência empírica, criticar a dicotomia entre o natural e o artificial (cultural), já que consideramos que a separação entre natureza e cultura vai além do suposto natural como transformador de uma ordem social e do social como ente transformador de uma suposta ordem natural.

A orientação sexual, ou identidade sexual do desejo, trata-se da atração psicoemocional, afetiva, erótica ou sexual por alguém de um ou mais gênero(s). Assim, esse conceito caracteriza-se como a capacidade de 
responder eroticamente a determinados estímulos que possuem eficácia sensorial, ou seja, que são capazes de provocar uma reação sensitivo-perceptual (Caravaca-Morera; Padilha, 2017a). Nesse ponto de vista, a orientação sexual se caracteriza pela ativação dos circuitos cerebrais responsáveis pelo desejo, ou seja, do incremento da vontade de viver uma experiência de prazer psicoemocional, afetivo ou erótico com outro ser. Logo, a transexualidade não está relacionada estritamente à sexualidade, mas especialmente a questões de gênero (Sirotheau; Pinheiro, 2015).

A definição do termo "orientação sexual" envolveu a consulta a diversos pesquisadores na área de estudos de gênero e sexualidade. Este termo fortalece a separação entre performance de gênero e desejo sexual, propiciando o afastamento do estigma da efeminação. Assim, ao propor a inclusão do termo, busca-se formalizar que a "diferença" na experiência homossexual está relacionada a se desejar uma pessoa do mesmo sexo e não a desejar ser do sexo oposto (Carvalho; Carrara, 2013).

Já o termo "identidade de gênero" fortaleceu sua definição em meio ao debate sobre transexualidade no movimento LGBT, no final dos anos 1990 e início dos anos 200o. Configurou-se como fator imprescindível na consolidação da distinção identitária entre travestis, transgêneros e transexuais de um lado; e gays, lésbicas, pansexuais, assexuais e bissexuais de outro. As primeiras passam a realizar suas reivindicações relacionados à identidade de gênero; os segundos, referentes à orientação sexual (Carvalho; Carrara, 2013).

Nesse sentido, a identidade de gênero diz respeito a como as pessoas se tornam e se percebem socialmente (masculino/feminino/não binários), não apenas considerando seu sexo assignado ao nascimento (Jesus, 2012). Por essa razão, ela pode ser considerada como autoidentificação e a convicção pessoal de pertencer ao gênero masculino, feminino, a ambos ou a nenhum.

Complementarmente, a discriminação pode ser compreendida como um fator desencadeante do sofrimento vivido pelas pessoas que se autoidentificam como transexuais, principalmente quando, devido às normas sociais rígidas sobre papéis de gênero e ao medo de punição, muitas vezes por parte da família, acabam desistindo de experienciar a vida conforme sua identidade de gênero (Sampaio; Coelho, 2012).

Outra questão que causa significativo sofrimento às pessoas é a patologização da transexualidade, considerada ainda pelo Manual Diagnóstico e Estatístico de Transtornos Mentais da Associação Americana de Psiquiatria (DSM) como uma disforia de gênero. Quando se determina que uma pessoa transexual é "doente" ou têm um "transtorno", está-se aprisionando-a e assumindo uma visão de mundo dualista e polarizada, medicalizando tudo aquilo que escapa do padrão cis-heteronormativo (Caravaca-Morera; Padilha, 2017b; Carvalho et al., 2016).

Dessa forma, uma das ferramentas de diálogo acerca das questões de identidade de gênero é a internet. Em outras palavras, a internet pode afetar, influenciar, mediar ou moldar o modo de pensar das pessoas, ou seja, conduzir opiniões e/ou comportamentos (Alexandre, 2001); Isto por se tratar de um instrumento capaz de reforçar as opiniões, atitudes e conhecimentos e a sua consequente divulgação. Além disso, dá a possibilidade de afirmar o peso do saber/poder dos valores hegemônicos, dada sua função instrumental de propaganda.

Nesse mesmo âmbito, o uso das redes sociais para exposição de opiniões é consequência das possibilidades de segurança e não cerceamento à fala. O sujeito que não teria condições de falar em público, o faz na internet; mas igualmente propicia um vasto espaço para discursos de ódio e promotores de violência extrema. Assim, o que pode se denominar como autonomia e liberdade individual, também pode se constituir como uma armadilha, que transforma a expressão de opinião de uma pessoa em processo de convencimento na fala de um(a) agressor(a) (Carvalho, 2017).

A comunicação pode oportunizar a compreensão das representações sociais, em especial os meios de comunicação em massa. Dessa maneira, as mídias em massa podem transformar os fenômenos sociais, disseminando para a população informações com vistas à produção de coesão social, visão social e de si mesmo; portanto, é um meio suscitador de representações sociais para a população (Alexandre, 2001). Ao aprofundar sobre as representações sociais, compreendemos que são estruturas cognitivas que outorgam de sentido ao mundo para compreendê-lo 
reforçando os simbolismos e as práticas materiais (Moscovici, 2015).

Diante do exposto, percebemos a internet como um local aberto à grande maioria da população, o que pode oportunizar a identificação das representações sociais da população sobre um determinado tema que no momento está em debate. Por conseguinte, observamos as manifestações da população sobre o tema da transexualidade devido a uma série de reportagens disponibilizadas por um programa jornalístico brasileiro de repercussão nacional, o qual levantou a questão da identidade de gênero ao debate popular e permitiu-nos formular a seguinte questão norteadora: quais as representações sociais sobre a transexualidade por meio de suas manifestações nas redes sociais? Neste sentido, este estudo tem por objetivo identificar as representações sociais sobre transexualidade com base nos comentários descritos nas redes sociais a partir de uma série de reportagens deste programa jornalístico.

\section{Método}

Trata-se de um estudo com abordagem qualitativa do tipo exploratório descritivo, utilizando-se o método da pesquisa documental (Gil, 2008) e alicerçada na teoria das representações sociais (Moscovici, 2015). É importante destacar que "a pesquisa documental vale-se de materiais que não receberam ainda um tratamento analítico, ou ainda que podem ser reelaborados de acordo com objetivos da pesquisa" (Gil, 2008, p. 51).0 documento se constitui como fonte de significativa importância para a pesquisa documental, e tem como foco a busca de informação em materiais que nunca receberam tratamento analítico científico, como jornais, relatórios, entre outros materiais (Teodosio et al., 2016).

As fontes de pesquisa utilizadas neste estudo foram comentários das publicações nas redes sociais (Facebook e Instagram), geradas por telespectadores de uma série sobre transexualidade e suas origens. Essa série foi divulgada em um programa jornalístico de televisão aberta, com abrangência nacional. Cabe ressaltar que a divulgação dos programas apresentava a transexualidade a partir de uma origem biológica, destacando casos de pessoas transexuais desde a infância e suas repercussões sociais.
A série de TV com quatro episódios foi disponibilizada online entre os meses de abril e maio do ano de 2017, por meio do site da emissora, sendo compartilhadas as chamadas de divulgação, dentre outras publicações, sobre a referida série nas redes sociais do programa. Seus compartilhamentos geraram, até 21 de maio, 1.292 comentários dos leitores.

A análise dos dados foi orientada pela técnica de análise de conteúdo, dividida em três fases: pré-análise; exploração do material; e tratamento dos resultados e interpretação (Bardin, 2011). Na pré-análise, foram selecionados e copiados todos os comentários e inseridos em um programa de edição de texto. A partir disso, fez-se sua seleção e refinamento, que objetivou retirar palavras incompreensíveis, abreviaturas, emoticons, comentários fora do objeto de investigação e marcações de pessoas, o que resultou em 770 comentários.

Na exploração do material, o arquivo de edição de texto com os comentários foi inserido no software Atlas.ti (Friese, 2014), com vistas à seleção de trechos de comentários (quotations), criação de códigos, representados por uma palavra ou um conjunto palavras que sintetizam o trecho do comentário.

No tratamento dos resultados e interpretação, os códigos foram agrupados em quatro grupos de códigos ou categorias, dispostos em redes (networks), realizou-se, dentro do software, mecanismos de análises como a coocorrência, índice de frequências, word cloud, visando a melhor compreensão do fenômeno investigado.

Por se tratar de um estudo documental de acesso público, dispensou a submissão ao Comitê de Ética e Pesquisa. Todavia, para garantir o anonimato dos comentários, foram identificados os participantes segundo a identificação de gênero, a saber: masculino e feminino. Essa definição foi obtida com base na visualização de cada perfil dos autores dos comentários em sua rede social.

\section{Resultados e discussão}

A organização dos dados oportunizou a análise de 770 trechos de comentários que foram vinculados a 14 códigos. A Tabela 1 ilustra o número de trechos de comentários relacionados aos códigos: 
Tabela I - Número de trechos de comentários relacionados aos códigos das representações sociais da transexualidade em redes sociais

\begin{tabular}{lll} 
& & Trechos de falas \\
Códigos & $n$ & $\%$ \\
Atitude desfavorável & 217 & 29 \\
\hline Atitude favorável & 189 & 25 \\
\hline Origem biológica & 93 & 12 \\
\hline Padrão heterocisnormativo & 89 & 11 \\
\hline Contrária a Deus & 78 & 10 \\
\hline Patologização trans & 33 & 4 \\
\hline Criação e aceitação de Deus & 15 & 2 \\
\hline Trans como opção & 15 & 2 \\
\hline Trans como condição biológica & 12 & 1,5 \\
\hline Ameaça & 10 & 1 \\
\hline Subjetividade da vivência trans & 7 & 0,9 \\
\hline Trans como algo natural & 6 & 0,8 \\
\hline Identidade de gênero & 5 & 0,7 \\
\hline Falta de oportunidades & 170 & 100 \\
\hline Total & 10,1 \\
\hline
\end{tabular}

Os 14 códigos foram agrupados em quatro transexualidade; definição de transexualidade; e grupos de códigos ou categorias, a saber: vulnerabilidade trans. A Figura 1 demonstra a relação origem da transexualidade; atitude em relação à dos códigos com os grupos de códigos:

\section{Figura I - Relação entre os códigos e as categorias de comentários sobre transexualidade nas redes sociais}

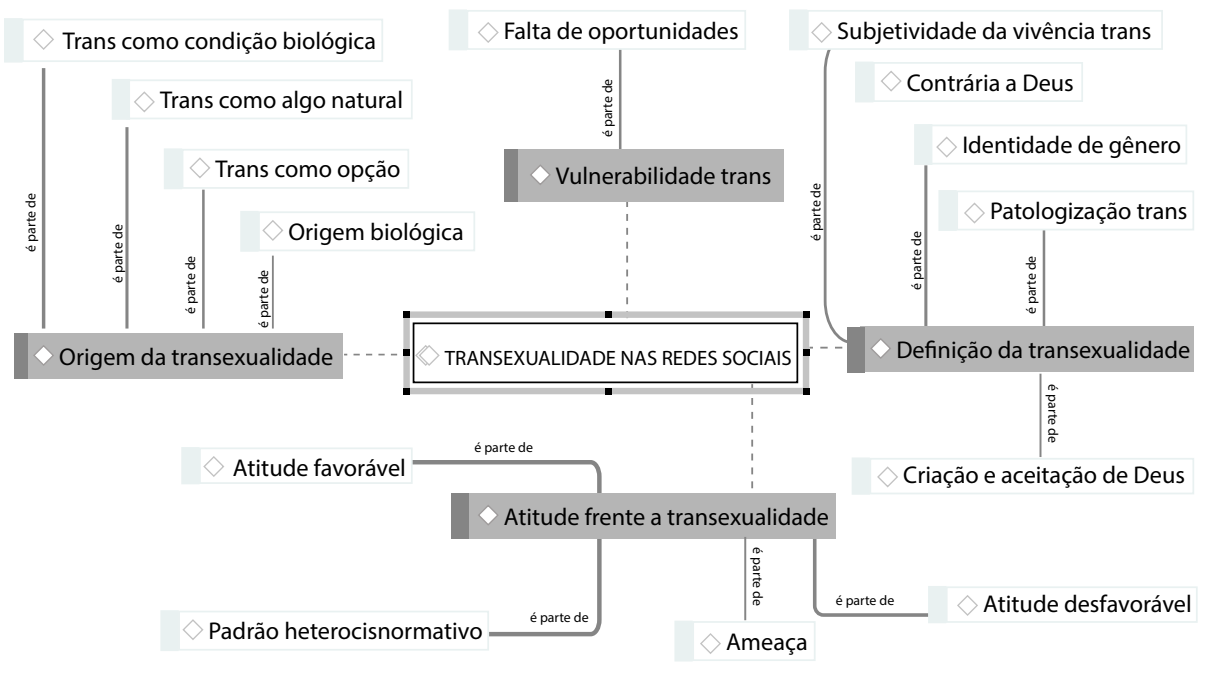




\section{Atitude em relação à transexualidade}

No grupo de códigos Atitude em relação à transexualidade encontra-se o código Ameaça, com 10 ocorrências, conforme comentário a seguir:

Engraçado uma coisa! Por que todo trans que aparece seja lá em qual for o lugar, é sempre homens??? Estranho isso não? Pode ser loucura da minha parte, mais parece que tem coisas por ai tentando destruir o homem. Pois saibam, quando isso acontecer o mundo também será destruído, se com homens é ruim imaginam sem eles??? Queiram vocês ou não o mundo se ergueu sobe as mãos de homens com suas conquistas, invenções, inovações, descobertas etc. Claro!!! depois de Deus!!! esse é único. (Gênero masculino) ${ }^{1}$

Este comentário exemplifica a ameaça de destruição do imaginário do ser humano, em que o indivíduo fundamentalista exalta a pessoa cisheterossexual para demonstrar que a transexualidade ameaça as pessoas cis-heterossexuais e, portanto, a humanidade. As posturas fundamentalistas acreditam que aqueles diferentes deles representam uma ameaça à suas crenças e, portanto, devem ser convertidos, marginalizados, excluídos ou destruídos, pois "o fundamentalismo é uma tentativa de recuperar o não questionamento de uma tradição, normalmente visto como um retorno ao passado imaculado (real ou imaginário) da tradição" (Berger; Zijderveld, 2012, p. 66). Desse modo, as práticas identitárias ininteligíveis ou que subvertem a norma heterocispatriarcal, segundo o comentário anterior, devem passar desapercebidas, pois as expressões públicas constituem-se em ameaça para a maiorias, sendo que os preconceitos e observações as valoram como condutas anormais e desagradáveis.

Observa-se também que a discriminação dirigida às pessoas dissidentes justifica simbolicamente a (i) lógica normativa e política da heterocisgeneridade, cujas noções de verdade e poder controlam e vigilam as outras opções, condições e práticas sexuais. Ao mesmo tempo, subordinam os corpos ao comportamento padronizado (Caravaca-Morera; Padilha, 2017a).

O segundo código refere-se à atitude desfavorável que abrange 217 ocorrências. Estão presentes nessa categoria comentários que fazem referência à não aceitação das pessoas transexuais. 0 trecho seguinte exemplifica a categoria: Viadagem tá foda. O Brasil tá ferrado e vocês ficam introduzindo lixo em nossas famílias. Basta, homem é homem e mulher é mulher, o resto, sem vergonhice (Gênero masculino).

Os comentários desfavoráveis, em geral, fazem referência à defesa de um modelo familiar tradicional-ortodoxo a ser preservado. A família nuclear caracterizada biologicamente por pai, mãe e filhos cisgêneros e heterossexuais é o padrão vigente no ocidente (Zambrano, 2006). Tal definição remete à necessidade de generatividade, de dar continuidade à espécie e continuar existindo a partir de um outro (Rabello; Passos, 2008). Portanto, a família oriunda de laços afetivos parece ser desconsiderada diante dessa representação.

Ainda, é possível perceber que questões relacionadas à sexualidade e ao gênero são confundidas e retratadas no imaginário popular e nas mídias como sinônimos. Além de serem consideradas como algo sujo, perigoso e feio, devendo ser censurados, não legitimados ou comentados (Rubin, 2003).

Paradoxalmente (ou talvez por isto), a sexualidade e o gênero representam o maior ponto cego do pensamento hodierno: subsidiário, derivado, supérfluo, enganoso, perigoso e até perverso que reforçam uma única forma de ser, atuar e pensar. Nega-se a possível (além de necessária) crítica ao binarismo e não contempla a total pluralização e flexibilização dessas estruturas, para além dos paradigmas estáticos, tradicionais e rígidos.

0 terceiro código refere-se à atitude favorável, contendo 189 ocorrências. Fazem parte dessa categoria comentários que parabenizam a reportagem, aqueles que fizeram parte dela, além de pessoas que defendem a compreensão de identidade de gênero. Segue um exemplo: São muito bem vindas. Merecem o mesmo respeito e amor, as mesmas oportunidades! Excelente essa série! (Gênero feminino). 
A busca pelo reconhecimento e aceitação das pessoas autoidentificadas como trans torna-se um processo complexo e requer muitos artifícios sociais para ser validado. Aqui, o reconhecimento legal da nova identidade não é somente um assunto de importância prática e instrumental para a pessoa trans, mas se constitui em uma forma de satisfazer a necessidade de aceitação dos outros de sua identidade.

Muitos dos comentários favoráveis à transexualidade faziam oposição à discriminação e preconceito sob a forma de ataque direto aos autores dos comentários discriminatórios, o que remete ao conceito de identidade social: "O processo de organizar o ambiente realça o exercício de efetuar julgamentos, incluindo o próprio indivíduo, que dessa forma adquire a consciência de pertencer a um grupo" (Del Prette; Del Prette, 2003, p. 127).

0 último código deste grupo de códigos se refere ao padrão heterocisnormativo, que contém 89 ocorrências. Abarca-se os comentários que traziam um discurso de cristalização dos papéis de gêneros femininos e masculinos:

Sabe de quem tenho dó? Dos pais, porque hoje sou pai de família, quando soube que teria um filho homem, já me veio na cabeça um companheiro para a vida toda, um cara pra discutir sobre futebol, ajudar a consertar o carro, tomar uma cerveja e assar uma carne no final de semana como héteros, pai e filho. Agora imagina a decepção deste pai! (Gênero masculino)

É possível identificar nas ocorrências um discurso heterocisnormativo que considera a impossibilidade de a identidade de gênero diferir do sexo assignado ao nascimento. Esses comentários são resultantes da apropriação de comportamentos e práticas de acordo com as normas de gênero impostas, ou seja, de acordo com a matriz binária normativa, sendo muitas vezes excluídos (inclusive por suas famílias) os que diferem desse padrão (Carvalho et al., 2016).

O conceito de cisgeneridade está presente nos discursos reforçando os padrões normativos sociais ocidentais, como a pessoa branca e cristã que norteia a vida da população, sendo esse o padrão naturalizado como verdade social, situado em diversos espaços e forçado nas vivências de todas as pessoas (Simakawa, 2015).

\section{Definição da transexualidade}

O próximo grupo de códigos é a definição da transexualidade que conta com cinco códigos, sendo o primeiro deles o código contrária a Deus, com 78 ocorrências. Nela estão trechos que tratam a transexualidade como oposta à criação divina, a saber: Deus fez macho e fêmea e não trans, isso é invenção de satanás pra enganar estas pessoas e levar para o inferno (Gênero masculino).

Os discursos religiosos podem seguir por duas vertentes: de acolhimento ou de combate. A vertente que busca o enfrentamento das diversidades de gênero e sexuais se baseia na atribuição de valor negativo aos que não seguem o padrão heterocisnormativo, considerando-os como um risco à população (Colling; Sant'Ana, 2014; Natividade; Oliveira, 2009). Assim, todos os avanços em questão do reconhecimento de direitos desse claustro populacional são considerados como um ataque às crenças morais, religiosas e ao padrão heteronormativo que rege o padrão familiar cisgênero aceitável.

O código criação e aceitação de Deus traz 15 ocorrências que trazem em seu discurso a ideia de que, se a transexualidade existe em nossa sociedade, ela foi criada e/ou é aceita por Deus:

Esse discurso de que Deus fez homem e mulher e só ta podre. Fez trans também se não, não nasceriam. Ninguém escolhe ser trans, a pessoa nasce trans do mesmo jeito que nasce branco, negro, pardo. Não éuma questão de escolha, princípio ou religião. Deus fez todos aceita que é melhor que excluir. (Gênero feminino)

Os posicionamentos com relação à população LGBT variam de acordo com a instituição religiosa. Há alguns segmentos religiosos que tratam a identidade de gênero e orientação sexual como expressão de fé, enquanto outros se posicionam de forma a aceitar as diferentes expressões sexuais das pessoas devido à concepção de amar uns aos outros e amor universal propagado em seu discurso (Musskopf, 2013). Deve-se considerar também que a atitude varia de acordo com cada sujeito individualmente, não apenas derivando da concepção de sua religião.

Relacionado à aceitação, hoje no cenário global têm-se a campanha Stop Trans Patologization que 
defende o direito de todas as pessoas expressarem seus atributos femininos e masculinos, além de modificarem livremente seus corpos, adequando-o às suas necessidades pessoais, sem serem classificadas por isso (Almeida; Murta, 2013).

No código identidade de gênero há cinco ocorrências. Nessa categoria foram inseridos os discursos que identificam a transexualidade como forma de expressão de gênero de acordo com o seu senso de pertencimento a um gênero, como por exemplo: Eu nascimulher, mas tenho respeito e amor por pessoas que nasceram num corpo que não se sente seu, deve ser uma situação horrível, todos merecem respeito e muito amor, eu amo vocês (Gênero feminino).

Observando as ocorrências, foi possível perceber que poucas pessoas diferenciaram identidade de gênero do sexo assignado ao nascimento. Há necessidade de compreensão da definição de ambos, devido à confusão originada pela não diferenciação dos conceitos, e também à necessidade de compreender que o sexo assignado ao nascimento não define a identidade de gênero das pessoas, pois a aceitação muitas vezes pode partir desse entendimento da não linearidade entre o componente biológico, o gênero e a identidade de gênero, como o exemplo citado (Almeida; Murta, 2013; Sampaio; Coelho, 2012).

O próximo código trata da patologização trans, com 33 ocorrências. Aqui estão inseridos os discursos que tratam a transexualidade como um transtorno associado à anormalidade, tendo em vista um padrão social heterocisnormativo. Como exemplo dessa categoria:

Não é mulher. Não queiram enfiar na nossa cabeça algo impossivel de existir. Ninguém se torna mulher, se nasce mulher. O máximo que pode acontecer é um homem se mutilar e virar uma caricatura de mulher. Mulher não é um sentimento. É uma realidade biológica. Fiquei horrorizada quando vi numa dessas reportagens que iriam tirar um pedaço do intestino do rapaz pra fazer o canal vaginal! Que absurdo é esse?! É trans de transtorno e pra isso existe tratamento. A pessoa deve ser conduzida a se encaixar no sexo que nasceu. Depois de fazer essa mutilação a pessoa transtornada enxerga o óbvio: é impossível pertencer ao sexo oposto. (Gênero feminino)
É possível perceber no discurso o ódio e a aversão causados pela diferença da identidade de gênero ao sexo assignado ao nascimento, sendo considerado transtorno devido à não adequação ao padrão heterocisnormativo. As vivências que fogem desse padrão binário são consideradas anormais e inclusive patológicas, com base no saber médico, discurso jurídico, doutrina religiosa e ciências biológicas, sendo considerado disforia de gênero de acordo com o Manual Diagnóstico e Estatístico de Transtornos Mentais (DSM) (Carvalho et al., 2016).

Carvalho et al. (2016) também discutem que a patologização, juntamente com a exclusão e a violência, podem ser meios de punição aos que diferem do padrão e que o discurso médico patologizador pode ser utilizado como forma de autenticar o discurso transfóbico.

Há uma distinção do pressuposto da patologização do discurso científico e do discurso de senso comum. Para o discurso científico, a correção da patologia seria a cirurgia; já para o senso comum, seria a expressão de gênero conforme o sexo assignado em nascimento. O discurso médico está impregnado das considerações sobre a aversão dos sujeitos pela genitália, por isso a cirurgia de reafirmação de gênero é considerada a única alternativa terapêutica para essas pessoas (Dias; Zenevich, 2014).

O último código trata da subjetividade da vivência trans, com sete ocorrências. Nessa categoria estão os discursos que trazem a necessidade de analisar individualmente os casos de cada pessoa transexual:

Condições físicas éuma coisa, condições emocionais, intelectuais, psicológicas é outra coisa, exemplo: uma pessoa que nasce sem algum membro do corpo (tipo uma perna) não pode querer colocar uma perna? Ou uma pessoa que nasce com um membro a mais (um braço) não pode querer amputar esse a mais? Isto é complexo demais, algo que tem que serrefletido muito mais por aquele ou aquela que sofre com isto, e também por doutores do corpo e da mente. (Gênero masculino)

No comentário, há a comparação da cirurgia de reafirmação de gênero com outros tipos de procedimentos cirúrgicos, trazendo a preocupação de analisar em cada caso a necessidade e desejo de realizar a cirurgia. A cirurgia muitas vezes é 
vista como a única forma de amenizar o sofrimento da pessoa transexual, generalizando a vivência trans. Nem toda pessoa que se autoidentifica como transexual deseja realizar a cirurgia ou sofre com o seu corpo (Sirotheau; Pinheiro, 2015). Dessa forma, foi também abordada nesta categoria a não generalização do sofrimento com o corpo como característico da população trans, devendo ser respeitadas as singularidades de cada pessoa transexual.

\section{Origem da transexualidade}

A terceira categoria sustenta a origem da transexualidade, possuindo quatro códigos. 0 código origem biológica conta com 93 ocorrências e apresenta comentários que possuem o discurso negativo e confirmam-no com base biológica, como exemplo:

Foi amamentado pelo pai? Vixi, Fantástico, se amamenta é porque, sem sombra de dúvidas, é uma mulher! Vocês sabem bem melhor que um pai, ou uma entidade biológica do sexo masculino não amamenta em nenhuma espécie do reino animal. Cortar a genitália de um homem não o transforma em mulher. Porque nós, mulheres temos características biológicas distintas, como período menstruais, uma vagina, clitóris, um útero, trompas, ovulação, podemos engravidar, carregar uma criança por nove meses, dar a luz a filhos, amamentar, ser mães, temos muita intuição feminina, etc. (Gênero feminino)

Aqui é possível identificar a não conformidade com a possibilidade de sair do padrão binário heteronormativo, sendo uma forma de poder e controle social (Quintela, 2013). O padrão heteronormativo estabelece a dicotomia homem/masculino e mulher/ feminino; logo, a sexualidade deve ser coerente ao sexo assignado ao nascimento, portanto, natural.

Contudo, as pessoas transexuais burlam o preestabelecido como supostamente biológico, natural. Quintela (2013) continua, expondo a questão das imposições e restrições que o padrão heterocisnormativo exerce na população, tornando obrigatória a adequação de papéis e comportamentos de acordo com o sexo assignado ao nascimento, sendo que os que não seguem esse padrão restritivo passam pelo que Bento (2008) considera como heteroterrorismo: inibição, violência e não reconhecimento.

O código trans como algo natural possui seis ocorrências que parabenizam a iniciativa da reportagem, a necessidade de falar sobre o tema e aceitação das pessoas transexuais. Como: Tem pessoas que não sabem o que dizem pessoas preconceituosas isso sim e ridículo, tenho é pena de certas pessoas, cada um vive do jeito e da maneira que quer (Gênero feminino).

A dificuldade de aceitação das pessoas transexuais se deve ao forte enraizamento à cultura heterocisnormativa, pois há reforço constante desse padrão nas mídias e relações familiares e sociais dos sujeitos (Quintela, 2013). Assim, a resistência pelo reconhecimento da pluralidade sexo-genérica se configura como um exercício cotidiano de subjetividade que é reforçado por diversas artimanhas necropolíticas da internet e os diferentes meios de comunicação coletiva. Dessa forma, quando a mídia e/ou os indivíduos se adaptam ao discurso legitimador da transexualidade, esse discurso passa a ter influência e autoridade.

O código trans como condição biológica traz 12 ocorrências que identificam em seu discurso a aceitação da transexualidade a partir da identificação de sua causa: Esse documentário que além de utilidade pública, ainda mostra com uma delicadeza sem igual a vida dessas pessoas que são tão descriminadas pelos que não conhecem essa condição do cérebro humano (Gênero feminino).

Esta ocorrência em específico traz em seu discurso uma visão extremamente biologicista como origem da transexualidade, desconsiderando aspectos sociais e culturais, psicológicos e relacionais. De acordo com Chiland (2008), busca-se estudar o cérebro das pessoas transexuais à procura de uma origem biológica para a transexualidade, mas não buscam entender as condições sociais nas quais estão inseridos esses indivíduos, nem se questiona o padrão heterocisnormativo imposto.

As pessoas sentem necessidade de atribuir uma causa (conexão) entre um evento e uma fonte, com o objetivo de buscar adequar a realidade exterior ao seu mundo interno, para ter a sensação de que o mundo é (na medida do possível) estável, controlável e previsível (Rodrigues, 1984). 
A partir do momento em que algum fenômeno foge do modelo causal, a resposta pode ser agressiva ou buscar o equilíbrio a partir da nova informação, essa última relacionada à mudança de representação sobre o fenômeno.

No código trans como opção há 15 ocorrências, sendo: Mas a Bỉblia é a Bỉblia e as pessoas têm também opiniões além da Bỉblia... Então não misture opções com religião! (Gênero masculino). Aqui é possível perceber a resposta a outra ocorrência de cunho religioso, que trata a questão da transexualidade como opção.

Nesse contexto, o indivíduo é responsabilizado pelas ações discriminatórias que sofre, tendo em vista que "escolheu" passar por elas. A estrutura da representação indica a necessidade de políticas públicas que priorizem a educação e orientação sexual, que esclareçam as faces da sexualidade e gênero humanos e suas formas de manifestações (Neves et al., 2015).

\section{Vulnerabilidade trans}

No grupo de códigos vulnerabilidade trans, o código falta de oportunidades traz uma ocorrência sobre as dificuldades sofridas pelas pessoas transexuais:

Seu lindo não ofendi você, só digo que não é você que foi abandonado pelos pais e nem tá na rua se prostituindo por falta oportunidade de emprego, tem sim de se abordar um assunto que para muitosé um tabú e pela falta de informações de muitos não saberem o que é ser uma pessoa trans, não nos abrem as portas e oportunidades... Então reveja seu conceito. (Gênero feminino)

Aqui, temos um relato da realidade vivida por muitas mulheres transexuais. A prostituição muitas vezes é o único espaço em que são aceitas, devido ao preconceito sofrido nos diferentes contextos: familiar, social e institucional, além de ser um dos poucos espaços onde são reconhecidas pelo gênero que se identificam (Giongo; Menegotto; Petters, 2012).

$\mathrm{O}$ estigma que sofrem as pessoas transexuais sexo-servidoras deve ser reconhecido e visto como um problema de saúde pública, pois obedece a processos de racionalização da dominação que exercem determinados sistemas sociais, neste caso, as representações sociais masculinas sobre as femininas.

O estigma e preconceito podem ser manifestados de diversas maneiras: pode ser difundido através de violência física ou psicológica, além da marginalização, levando-as à vulnerabilidade social. A ocultação da violência sofrida e a dificuldade de acesso ou respeito na saúde pública favorecem a vulnerabilidade social sofrida por esse grupo (Silva et al., 2016).

Desse modo, é possível considerar a influência dos meios de comunicação na eleição dos assuntos a serem discutidos socialmente. De um lado, a origem biológica na condição de causalidade pode ser utilizada como um discurso que simplifica a compreensão e gera a aceitação da pessoa transexual; de outro, essa mesma origem biológica é utilizada para justificar ações discriminatórias e representações sociais cujo núcleo são estereótipos.

\section{Considerações finais}

A pesquisa buscou identificar as representações sociais sobre transexualidade, sendo possível classificá-los em quatro grupos temáticos: origem da transexualidade, atitude em relação à transexualidade, definição de transexualidade e vulnerabilidade trans, a partir disso, foi possível identificar as representações sociais dos usuários das redes sociais em questão.

A importância da análise dos comentários da internet se deve ao fato da aparente liberdade que as redes sociais fornecem aos indivíduos, possibilitando que se sintam à vontade para discutir suas "opiniões" sobre o tema que é polêmico, gera divergências e conflitos, devido à pertença em diferentes grupos sociais ou crenças individuais. Dessa forma, foi possível analisar os dados e identificar as representações sociais dos usuários das redes sociais sobre o tema sem que se sintam intimidados em demonstrar seus verdadeiros núcleos representacionais, principalmente devido à delicadeza do tema tratado.

A falta de informação de parte dos internautas sobre a população LGBT e principalmente sobre as pessoas que se autoidentificam trans é nítida e preocupante. Essa "sem vergonhice" da falta de compreensão e respeito com as pessoas trans, aliado ao discurso culpabilizador, opressor e fundamentalista 
coopera para a vulnerabilidade delas, alocando-as às margens da sociedade de direito.

A análise dos comentários reforça a necessidade de ampliação de políticas públicas eficazes para a população nos diversos âmbitos e, consequentemente, a garantia dos direitos humanos e a cidadania. Os resultados sugerem ainda novas pesquisas com melhor caracterização dos indivíduos, de modo a conhecer seus grupos de pertença e a gênese de suas representações sociais, bem como sobre tópicos vinculados às populações socialmente vulnerabilizadas.

\section{Referências}

ALEXANDRE, M. O papel da mídia na difusão das representações sociais. Comum, Rio de Janeiro, v. 6, n. 17, p. 111-125, 2001.

ALMEIDA, G.; MURTA, D. Reflexões sobre a possibilidade da despatologização da transexualidade e a necessidade da assistência integral à saúde de transexuais no Brasil. Sexualidad, Salud y Sociedad, Rio de Janeiro, n. 14, p. 380-407, ago. 2013.

ANTRA - ASSOCIAÇÃO NACIONAL DE TRAVESTIS E TRANSEXUAIS. Mapa dos assassinatos de travestis e transexuais no Brasil em 2017. Brasília, DF, 2018. Disponível em: <http://bit.ly/2L1gLbE〉. Acesso em: 22 fev. 2019.

BARDIN, L. Análise de conteúdo. Lisboa:

Edições 70, 2011.

BENTO, B. O que é transexualidade. São Paulo: Brasiliense, 2008.

BERGER, P.; ZIJDERVELD, A. Em favor da dúvida: como ter conviç̧ões sem se tornar um fanático. Rio de Janeiro: Elsevier, 2012.

BRASIL. Ministério dos Direitos Humanos. Balanço das denúncias de violações de direitos humanos. Brasília, DF, 2016.

CARAVACA-MORERA, J. A.; PADILHA, M. I. Corpos em trânsito: espaços, emoções e representações que (des)constroem realidades. Revista da Escola de Enfermagem da USP, São Paulo, v. 51, p. 1-8, 2017 a.
CARAVACA-MORERA, J. A.; PADILHA, M. I.

Representações sociais do sexo e gênero entre pessoas trans. Revista Brasileira de Enfermagem, Brasília, DF, v. 7O, n. 6, p. 1235-1243, 2017b.

CARVALHO, A. P. G. B. et al. Patologizando o abjeto: a transexualidade como categoria diagnóstica.

Humanae, Recife, v. 10, n. 2, 2016. Não paginado. Disponível em: <http://bit.ly/30y55DO>. Acesso em: 29 maio 2017.

CARVALHO, M. F. L. Nossa esperança é ciborgue? Subalternidade, reconhecimento e "tretas" na internet. Estudos Feministas, Florianópolis, v. 25, n. 1, p. 347-363, 2017.

CARVALHO, M.; CARRARA, S. Em direito a um futuro trans? Contribuição para a história do movimento de travestis e transexuais no Brasil. Sexualid, Salud y Sociedad, Rio de Janeiro, n. 14, p. 319-351, ago. 2013.

CHILAND, C. O transexualismo. São Paulo: Loyola, 2008.

COLLING, L.; SANT'ANA, T. Um breve olhar sobre a transexualidade na mídia. In: COELHO, M. T. A. D.; SAMPAIO, L. L. P. (Org.). Transexualidades: um olhar multidisciplinar. Salvador: Edufba, 2014. p. 255-266.

DEL PRETTE, A.; DEL PRETTE, Z. Assertividade, sistema de crenças e identidade social.

Psicologia em Revista, Belo Horizonte, v. 9, n. 13, p. 125-136, 2003.

DIAS, M. B.; ZENEVICH, L. Um histórico da patologização da transexualidade e uma conclusão evidente: a diversidade é saudável. Gênero e Direito, João Pessoa, v. 3, n. 2, p. 11-23, 2014. Disponível em: <http://bit.ly/2KRdNrk>. Acesso em: 22 fev. 2018.

FEDORKO, B.; BERREDO, L. O círculo vicioso da violência: pessoas trans e gênero-diversas, migração e trabalho sexual. Berlim: Transrespeito versus Transfobia no Mundo, 2017.

FRIESE, S. Qualitative data analysis with ATLAS. ti. 2. ed. Londres: Sage, 2014.

GIL, A. C. Métodos e técnicas de pesquisa social. 6. ed. São Paulo: Atlas, 2008. 
GIONGO, C. R.; MENEGOTTO, L. M. O.; PETTERS, S. Travestis e transexuais profissionais do sexo: implicações da psicologia. Psicologia: Ciência e Profissão, Brasília, DF, v. 32, n. 4, p. 10oo-1013, 2012.

JESUS, J. G. Orientações sobre identidade de gênero: conceitos e termos. 2. ed. Brasília, DF, 2012. Disponível em: <http://bit.ly/2NqScaY>. Acesso em: 29 maio 2017.

MACHADO, P. S. O sexo dos anjos: um olhar sobre a anatomia e a produção do sexo (como se fosse) natural. Cadernos Pagu, Campinas, n. 24, p. 249281, ago. 2005.

\section{MOSCOVICI, S. Representações sociais:}

investigações em psicologia social. 11. ed. Petrópolis: Vozes, 2015.

MUSSKOPF, A. A relação entre diversidade religiosa e diversidade sexual: um desafio para os direitos humanos e o Estado laico. Estudos de Religião, São Paulo, v. 27, n. 1, p. 157-176, 2013.

NATIVIDADE, M. T.; OLIVEIRA, L. Sexualidades ameaçadoras: religião e homofobia(s) em discursos evangélicos conservadores. Sexualid, Saludy Sociedad, Rio de Janeiro, n. 2, p. 121-161, 2009.

NEVES, A. L. M. et al. Representações sociais de professores sobre diversidade sexual em uma escola paraense. Psicologia Escolar e Educacional, Maringá, v. 19, n. 2, p. 261-270, 2015.

QUINTELA, H. F. Navalha na carne: o não reconhecimento da transexualidade e suas consequências. In: FAZENDO GÊNERO:

DESAFIOS ATUAIS DOS FEMINISMOS, 10., 2013, Florianópolis. Anais... Florianópolis: UFSC, 2013. Disponível em: <http://bit.ly/2MCp2px>.

Acesso em: 12 jun. 17.

RABELLO, E.; PASSOS, J. S. Erikson e a teoria psicossocial do desenvolvimento. 2008. Disponível em: <http://bit.ly/2U2WCpJ>. Acesso em: 12 jun. 17.

RODRIGUES, A. Atribuição de causalidade: estudos brasileiros. Arquivos Brasileiros de Psicologia, Rio de Janeiro, v. 36, n. 2, p. 5-20, 1984.

RUBIN, G. Pensando o sexo: notas para uma teoria radical das políticas da sexualidade. Cadernos Pagu, Campinas, n. 21, p. 1-88, 2003.
SAMPAIO, L. L. P.; COELHO, M. T. A. D.

Transexualidade: aspectos psicológicos e novas demandas ao setor de saúde. Interface: Comunicação, Saúde, Educação, Botucatu, v. 16, n. 42, p. 637-649, 2012.

SILVA, G. W. S. et al. Situações de violência contra travestis e transexuais em um município do nordeste brasileiro. Revista Gaúcha de Enfermagem, Porto Alegre, v. 37, n. 2, e56407, 2016. Disponível em: <http://bit.ly/30y8uT6>. Acesso em: 12 jun. 17.

SIMAKAWA, V. V. Por inflexões decoloniais de corpos e identidades de gênero inconformes: uma análise autoetnográfica da cisgeneridade como normatividade. Dissertação (Cultura e Sociedade) - Universidade Federal da Bahia, Salvador, 2015 .

SIROTHEAU, M. B.; PINHEIRO, M. D. C.

Transexualidade: a vivência dos sofrimentos da pessoa que reivindica ser aceita pelo gênero que pertence, independente da realização da cirurgia de transgenitalização. Em Foco, Santarém, v. 2, n. 24, p. 109-126, 2015. Disponível em: <http://bit. ly/2LovKCI $>$. Acesso em: 26 maio 2017.

TEODOSIO, S. S.-C. S. et al. A história oral e pesquisa documental como itinerário de pesquisa na enfermagem: um estudo bibliométrico (20002014). Escola Anna Nery, Rio de Janeiro, v. 2o, n. 4, e20160087, 2016.

ZAMBRANO, E. Parentalidades “impensáveis": pais/mães homossexuais, travestis e transexuais. Horizontes Antropológicos, Porto Alegre, v. 12, n. 26, p. 123-147, 2006.

\section{Contribuição dos autores}

Vitali e Castro conceberam e delinearam o estudo, analisaram e interpretaram os dados e, com Soratto e Caravaca-Morera, redigiram o artigo, realizaram a revisão crítica e aprovaram a versão final a ser publicada.

Recebido: 01/03/2019

Aprovado: 30/05/2019 